\title{
The rare case of giant cell tumor occuring in the axial skeleton after 15 years of follow-up: Case report
}

\author{
YE-SOO PARK $^{1}$, JIN KYU LEE ${ }^{1}$, SEUNG-WOOK BAEK ${ }^{1}$ and CHAN-KUM PARK ${ }^{2}$ \\ ${ }^{1}$ Department of Orthopaedic Surgery, Guri Hospital, 249-1; ${ }^{2}$ Department of Pathology, \\ Hanyang University College of Medicine, Seoul 133-791, Republic of Korea
}

Received May 12, 2011; Accepted August 24, 2011

DOI: $10.3892 / \mathrm{ol} .2011 .402$

\begin{abstract}
The majority of giant cell tumors (GCTs) occur in the ends of the long bones. The presence of more than one GCT in the axial skeleton is rare. A GCT is capable of remaining clinically latent following treatment and becoming active a number of years later. We report an extremely rare case of GCT occurring in the axial skeleton, involving the sacrum, thoracic spine and parieto-occipital skull in more than 15 years of follow-up.
\end{abstract}

\section{Introduction}

Giant cell tumors (GCTs) are benign tumors commonly occurring at the ends of the long bones, representing approximately $5 \%$ of bone tumors (1). GCTs rarely occur in the spine, with $2-5 \%$ of tumors found in the spine above the sacrum $(2,3)$. When occurring in the spine, these tumors most commonly present with localized pain and swelling of the affected side, and may also result in neurological deficit $(3,4)$.

In this study, the authors present an extremely rare case of GCT occurring in the axial skeleton, involving the sacrum, thoracic spine and parieto-occipital skull in more than 15 years of follow up. The study was approved by the Institutional Review Board (IRB) for Human Subjects Research and Ethics Committees of Hanyang University Guri Hospital, Korea.

\section{Case report}

In March 1993, a 24-year-old male without a significant past medical history presented with a several-month history of localized pain in the right buttock area. There was induration on the buttock and a firm, palpable mass.

Neurological examination revealed mild weakness of the flexor hallucis longus and flexor digitorum longus with

Correspondence to: Professor Ye-Soo Park, Department of Orthopaedic Surgery, Guri Hospital, Hanyang University College of Medicine, Kyunggi-do, Seoul 249-1, Republic of Korea

E-mail: hyparkys@hanyang.ac.kr

Key words: giant cell tumor, sacrum, spine, skull grade $4 / 5$ power. The patient experienced diminished sensation in the perineal region, and sphincter tone was slightly diminished. Radiographs revealed a large, osteolytic lesion involving almost the entire sacrum (Fig. 1). Computed tomography (CT) also revealed a destructive sacral mass involving almost the entire sacrum below the S1 vertebral body. T2-weighted magnetic resonance imaging (MRI) showed an expansile soft tissue mass with a heterogeneous signal density. The tumor infiltrated into the spinal and sacral canal, and into the presacral area above S2 (Fig. 2). The technetium-99m methylene diphosphonate whole-body bone scan revealed an abnormally high uptake in the sacral region (Fig. 3). Metastases were not found. To prevent an improper diagnosis or a delay in treatment occurring, open biopsy was performed from the posterior aspect of the sacrum, and histopathological examination revealed numerous multinucleated giant cells within a background of scant stroma consistent with GCT (Fig. 4).

With the goal of pain relief, tumor resection and prevention of further neurological deterioration, the patient underwent high sacral amputation using a staged anterior and posterior approach. In the first stage, the anterior procedure with a transperitoneal approach was performed. The anterior aspect of the tumor was exposed, and internal iliac and middle sacral vessels were ligated. The anterior osteotomy was performed through the lower border of the $\mathrm{S} 1$ vertebral body at the level just below the S1 sacral foramina. In the second stage, the posterior approach was performed to transect the dural contents, eventually interconnecting the anterior and posterior osteotomies (Fig. 5). The tumor was resected with a small margin and the biopsy tract was included within the resection margins. The S1 roots were preserved. For adjuvant therapy, the patient underwent radiotherapy consisting of a total dose of $5000 \mathrm{rad}$ in 5 weeks.

Postoperatively, the patient was able to ambulate without the use of external supports by 6 months. A certain amount of perineal numbness remained, but the patient did not consider the lower extremity numbness to be particularly disabling. The patient suffered difficulties with urinary retention, requiring intermittent urinary self-catheterization. Self-urination and defecation became possible by a voluntary increase of the abdominal muscle pressure.

After 5 years, there was no evidence of local recurrence on serial imaging. The patient had returned to work without significant complaints and was satisfied with the degree of mobility. 


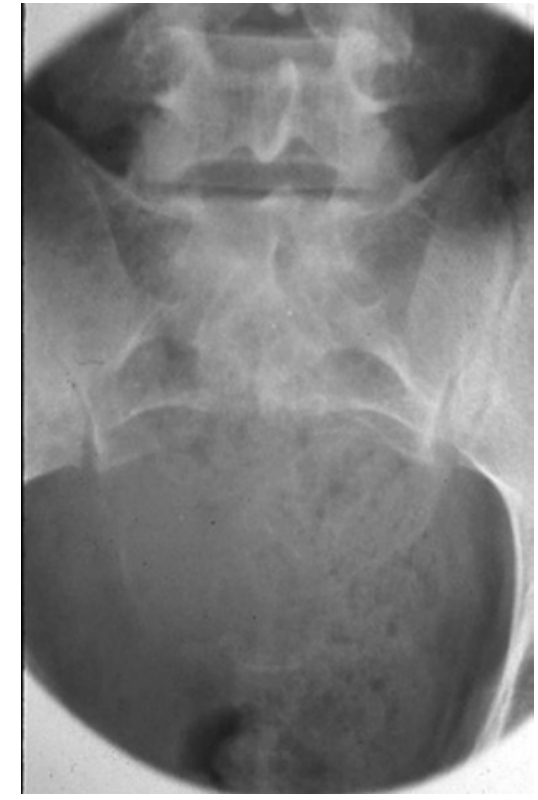

Figure 1. An anteroposterior plain radiograph shows an osteolytic area involving almost the entire sacrum below the S1 vertebral body.

In March 2008, the patient reported increasing pain in the back and mid-buttock area. Physical examination of the buttock area revealed a draining sinus on the previous surgery scar with pus-like discharge. MRI of the lumbar and thoracic spine was performed. T2-weighted MRI of the lumbar spine revealed high signal intensity pus draining with a sinus tract into the buttock area (Fig. 6A). MRI studies of the thoracic spine showed diffuse enhancement on the T11 vertebral body with an associated compression deformity suggestive of a bone tumor. There was no cord compression, nor a signal change within the cord (Fig. 6B). A technetium-99m methylene diphosphonate whole-body bone scan was also performed and showed abnormal uptake only at the T11 vertebral body.

Considering the patient's clinical history and findings on MRI, a diagnosis of metastatic GCT was considered, involving anterior zones of the vertebral body according to the Weinstein-Boriani-Biagini (WBB) classification system $(5,6)$. The patient subsequently underwent a wide en block resection of T11 and anterior interbody fusion with autogenous iliac strut bone graft. A complete resection of the vertebral body was achieved and specimens were sent for histopathological analysis. The spinal reconstruction and stabilization were performed by posterolateral fusion with autogenous iliac bone graft and pedicle screw fixation. Additionally, the patient had open irrigation and debridement for the infection on the buttock.

The histopathological examination revealed numerous multinucleated giant cells within a background of scant stroma, consistent with GCT. For adjunctive therapy, the patient again underwent radiotherapy consisting of a total dose of 5000 rads in 5 weeks.

In October 2008, the patient reported newly developed localized swelling on the right occipital area. A diffuse swelling was noted in the right parieto-occipital area. CT scan of the brain revealed a large well-defined hyper-

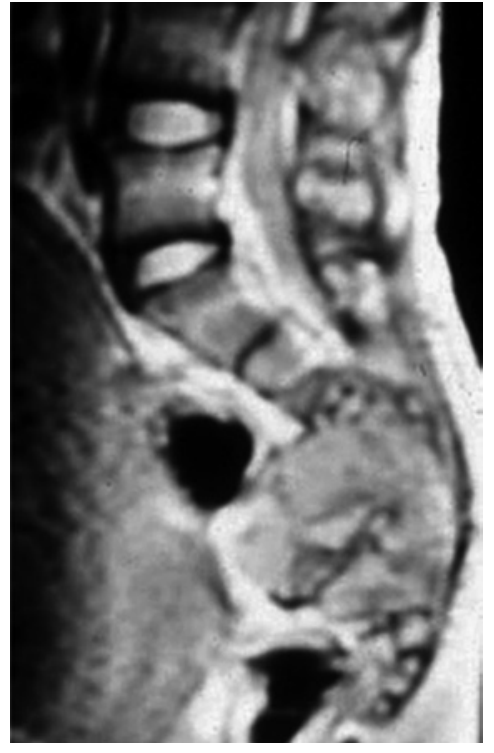

Figure 2. Sagittal T2-weighted magnetic resonance imaging shows an expansile soft tissue mass with a heterogeneous signal density with presacral extension.

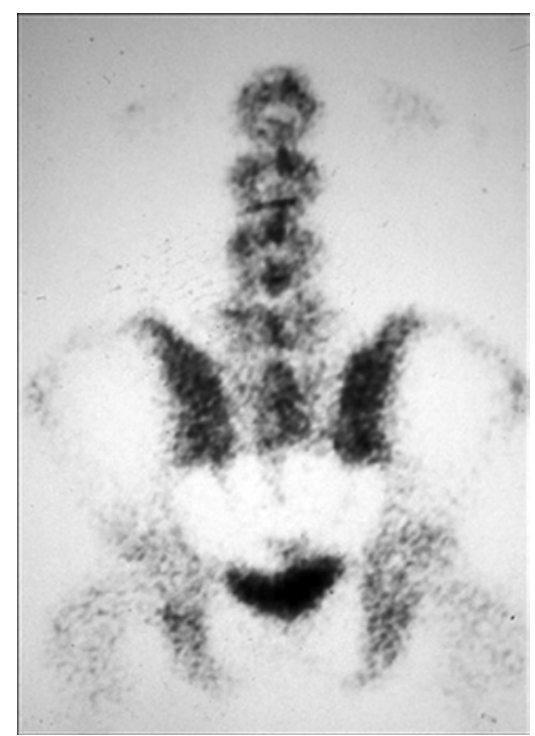

Figure 3. A technetium-99m methylene diphosphonate whole-body bone scan reveals a high uptake area in the sacrum.

dense contrast-enhancing lesion originating from the right parieto-occipital bone (Fig. 7). The patient subsequently underwent a right parieto-occipital craniectomy, followed by cranioplasty. Adjunctive radiotherapy was repeated. The histopathological examination has confirmed the diagnosis of GCT of bone.

Currently, the patient continues to be free of recurrence 26 months following the T11 corpectomy, and 19 months following the craniectomy.

\section{Discussion}

The majority of GCTs occur in the ends of the long bones, usually the distal femur, proximal tibia and distal radius $(1,2)$. GCTs rarely occur in the spine, with $2-5 \%$ of tumors found 


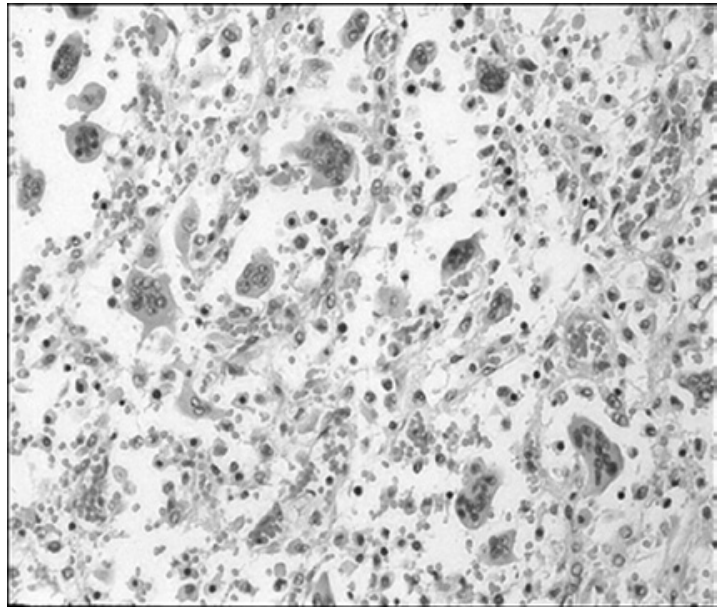

Figure 4. Hematoxylin and eosin (H\&E)-stained biopsy specimen shows multinucleated giant cells within a background of stromal cells (original magnification, $\mathrm{x} 400$ ).

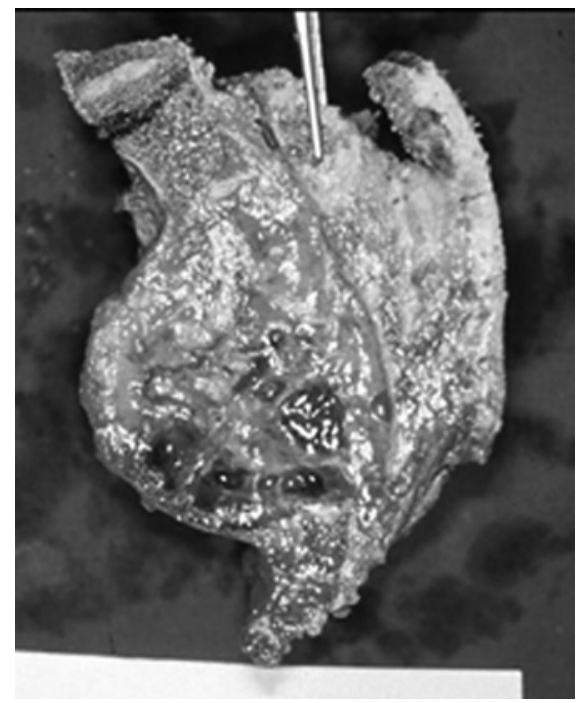

Figure 5. Osteotomy was performed through the lower border of the S1 vertebral body at the level just below the S1 sacral foramina.

in the spine above the sacrum (2-4). Neoplasia of the skull bones are also extremely rare, accounting for only $2.4-2.6 \%$ of all primary bone tumors, and when they occur, the sphenoid bone is known to be the most common site, followed by the temporal bone $(5,7)$. Although GCTs exhibit a propensity for aggressive local recurrence, there are few reports of metastases or recurrence from GCT of the spine. Additionally, GCTs are difficult to determine due to the low incidence of these lesions $(2,4)$.

Multifocal GCTs of bone have been addressed in previous reports, mostly occurring in the limbs. On only one occasion has the multifocal GCT of bone been reported in the spine, occurring primarily in the thoracic spine, and two years later, in the sacrum (8). Due to multiple lesions in the axial skeleton in the absence of lung involvement and an open foramen ovale, it is difficult to confirm whether the tumors were actually multifocal in their origin or spread through the vertebral venous complex $(9,10)$. The Batson's venous plexus,

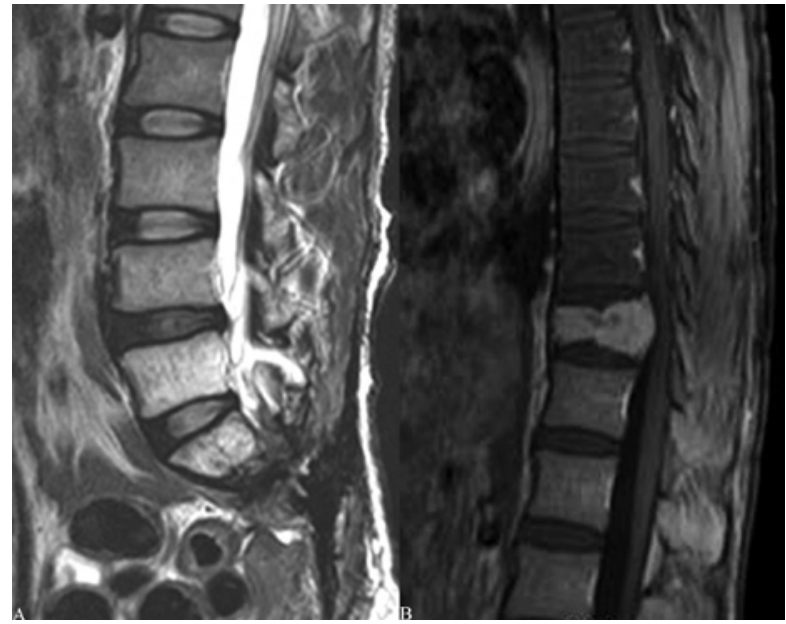

Figure 6. (A) Sagittal T2-weighted magnetic resonance imaging (MRI) shows high signal intensity pus draining with a sinus tract at the posterior aspect of the L5 vertebral body. (B) Sagittal T1-weighted enhanced MRI of the thoracic spine shows diffuse enhancement on the T11 vertebral body with an associated compression deformity.

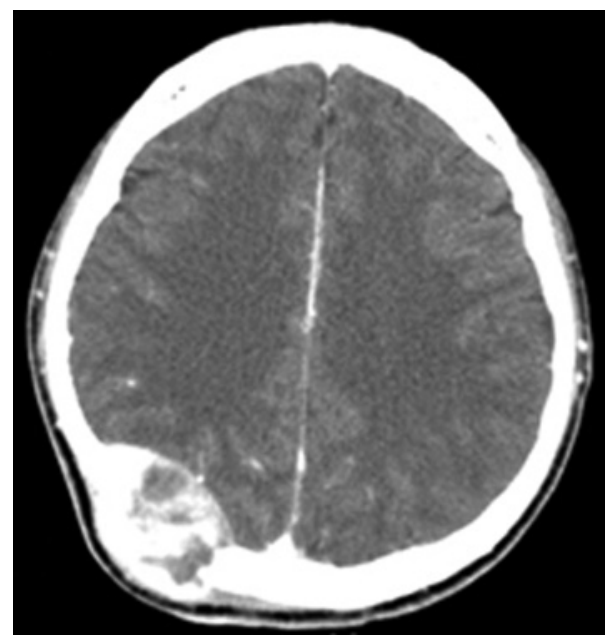

Figure 7. An axial computed tomography imaging scan of the brain shows a large well-defined hyperdense contrast enhancing lesion originating from the right parieto-occipital area tract.

which connects the deep pelvic veins to the internal vertebral venous plexuses, may provide a route for the spread of tumors arising from the pelvis to the vertebral column or brain (10). The primary tumor and metastatic lesions usually have the same histological features; however, histological grades and findings do not have practical value in the prediction of the outcome or the risk of metastatic spread $(11,12)$.

Optimal management of GCT of bone is known to be complete resection of the tumor with wide margins if possible, and according to Mnaymneh et al (13), there was no recurrence when the primary tumor excision was performed, whereas recurrent malignant changes were reported in approximately half or more of groups undergoing curettage and irradiation $(3,14)$. Due to the propensity of GCTs for aggressive local recurrence, adjuvant radiation therapy to the resection site may be adopted. Although it is widely held that radiation is capable of inducing sarcomatous transformation and soft tissue damage, it has been suggested that this risk 
was possibly associated with the now obsolete ortho-voltage radiation therapy rather than the currently used mega-voltage radiation therapy (15-17). Fujimoto et al (18) report favorable results in three consecutive cases diagnosed with GCT of the spine, which were treated with radiotherapy and bisphosphonate $(\mathrm{BP})$ as a new treatment option.

In the present case, the patient was found to have multifocal GCTs in extremely unusual locations. The first in the sacrum, the second, 15 years later, in the thoracic spine, and the third, 15 years and 6 months later from the onset of the first tumor in the sacrum, in the parieto-occipital area of the skull. The patient had neither lung involvement nor a sign of cardiac septal defect. The tumors in the thoracic spine and skull may be thought of as metastases of the primary lesion in the sacrum with late recurrence. As the patient had an open biopsy for the initial diagnosis, it is possible that the biopsy margins were contaminated in the first resection and the infection of primary site, which occured 15 years later may be related to residual active disease $(15,19,20)$. The 15 -year interval between the primary lesion in the sacrum and recurrences in the thoracic spine and skull was longer than the usual interval that has been reported in other studies (19). Thus, we report an extremely rare case of GCT occurring in the axial skeleton, involving the sacrum, thoracic spine and parieto-occipital skull in more than 15 years of follow up.

\section{References}

1. Donthineni R, Boriani L, Ofluoglu O and Bandiera S: Metastatic behaviour of giant cell tumour of the spine. Int Orthop 33: 497-501, 2009.

2. Goldenberg RR, Campbell CJ and Bonfiglio M: Giant-cell tumor of bone. An analysis of two hundred and eighteen cases. J Bone Joint Surg Am 52: 619-664, 1970.

3. Sanjay BK, Sim FH, Unni KK, McLeod RA and Klassen RA: Giant-cell tumours of the spine. J Bone Joint Surg Br 75: $148-154,1993$.

4. Kumar R, Guinto FC Jr, Madewell JE, David R and Shirkhoda A: Expansile bone lesions of the vertebra. Radiographics 8: 749-769, 1988.
5. Bitoh S, Takimoto N, Nakagawa H, Namba J, Sakaki S and Gohma T: Giant cell tumor of the skull. Surg Neurol 9: 185-188, 1978.

6. Boriani S, Weinstein JN and Biagini R: Primary bone tumors of the spine. Terminology and surgical staging. Spine (Phila Pa 1976) 22: 1036-1044, 1997.

7. Bertoni F, Unni KK, Beabout JW and Ebersold MJ: Giant cell tumor of the skull. Cancer 70: 1124-1132, 1992.

8. Kos CB, Taconis WK, Fidler MW and ten Velden JJ: Multifocal giant cell tumors in the spine. A case report. Spine (Phila Pa 1976) 22: 821-822, 1997.

9. Onuigbo WI: Batson's theory of vertebral venous metastasis: a review. Oncology 32: 145-150, 1975.

10. Batson OV: The function of the vertebral veins and their role in the spread of metastases. Clin Orthop Relat Res 312: 4-9, 1995.

11. McGough RL, Rutledge J, Lewis VO, Lin PP and Yasko AW: Impact severity of local recurrence in giant cell tumor of bone. Clin Orthop Relat Res 438: 116-122, 2005.

12. Lausten GS, Jensen PK, Schiodt T and Lund B: Local recurrences in giant cell tumour of bone. long-term follow up of 31 cases. Int Orthop 20: 172-176, 1996.

13. Mnaymneh WA, Dudley HR and Mnaymneh LG: Giant-cell tumor of bone. an analysis and follow-up study of the forty-one cases observed at the Massachusetts General Hospital between 1925 and 1960. J Bone Joint Surg Am 46: 63-75, 1964.

14. Shikata J, Yamamuro T, Kotoura Y, Mikawa Y, Iida H and Maetani S: Total sacrectomy and reconstruction for primary tumors. report of two cases. J Bone Joint Surg Am 70: 122-125, 1988.

15. Refai D, Dunn GP and Santiago P: Giant cell tumor of the thoracic spine: case report and review of the literature. Surg Neurol 71: 228-233, 2009.

16. Caudell JJ, Ballo MT, Zagars GK, et al: Radiotherapy in the management of giant cell tumor of bone. Int J Radiat Oncol Biol Phys 57: 158-165, 2003.

17. Nair MK and Jyothirmayi R: Radiation therapy in the treatment of giant cell tumor of bone. Int J Radiat Oncol Biol Phys 43: 1065-1069, 1999.

18. Fujimoto N, Nakagawa K, Seichi A, et al: A new bisphosphonate treatment option for giant cell tumors. Oncol Rep 8: 643-647, 2001.

19. Bergh P, Kindblom LG, Gunterberg B, Remotti F, Ryd W and Meis-Kindblom JM: Prognostic factors in chordoma of the sacrum and mobile spine: a study of 39 patients. Cancer 88: 2122-2134, 2000.

20. Fourney DR, Rhines LD, Hentschel SJ, et al: En bloc resection of primary sacral tumors: classification of surgical approaches and outcome. J Neurosurg Spine 3: 111-122, 2005. 